\title{
O PAPEL DA VERDADE NA TEORIA DA RACIONALIDADE DE THOMAS KUHN
}

\author{
Adan John Gomes da Silva*
}

\begin{abstract}
Resumo
O trabalho tem como objetivo investigar a relação existente entre as ideias de Thomas Kuhn acerca da racionalidade científica e aquelas que dizem respeito à relação entre ciência e realidade. Nesse sentido, coloca o antirrealismo deste autor como um elemento essencial da teoria da racionalidade desenvolvida ao longo de sua obra, relação que deve ser corroborada ao explicar como esse antirrealismo é antes um pressuposto dessa teoria da racionalidade do que uma implicação necessária das observações históricas de Kuhn. No fim, o trabalho espera deixar claro que qualquer leitura desse autor que separe essas duas dimensões de sua obra correrá o risco de ignorar a profundidade de seu pensamento.
\end{abstract}

Palavras-chave: Ciência. Racionalidade. Thomas Kuhn. Verdade.

\begin{abstract}
The work aims to investigate the relationship between the ideas of Thomas Kuhn about scientific rationality and those related to the relationship between science and reality. In this sense, puts Kuhn's anti-realism as an essential element of the theory of rationality developed throughout his work, relationship that must be corroborated by explaining how this anti-realism is rather an assumption of this theory of rationality than a necessary implication of the historical observations of Kuhn. In the end, the work hopes to make clear that any reading of this author that separates these two dimensions of his work runs the risk of ignoring the depth of his thought.
\end{abstract}

Key-words: Science. Rationality. Thomas Kuhn. Truth.

\section{INTRODUÇÃO}

Racionalidade e verdade figuram como os dois principais temas na filosofia da ciência, razão pela qual é possível agrupar praticamente todos os filósofos da ciência influentes sob o debate desses temas. Thomas Kuhn não é uma exceção. Com efeito, além de sua obra ser vista tradicionalmente como um divisor de águas no que diz respeito aos

\footnotetext{
* Mestre em filosofia pela UFRN e Professor do Instituto Federal de Educação, Ciência e Tecnologia do Rio Grande do Norte. E-mail: adan.john@ifrn.edu.br. CV: http://lattes.cnpq.br/4180646289120287

DIALEKTIKÉ, v. 1, novembro 2014, p. 3-16

Artigo submetido em setembro/2014 e aceito em outubro/2014
} 
tratos dados à racionalidade científica, suas considerações acerca da relação entre ciência e realidade têm gozado de um renovado interesse nos últimos anos ${ }^{1}$. Este trabalho procura mostrar certa unidade do pensamento desse filósofo no que diz respeito a esses dois temas. Nesse sentido, ele mostra como Kuhn depende de seu antirrealismo científico a fim de prestar a sua descrição de ciência o elemento racional reclamado por seus críticos.

Para esse propósito o trabalho inicia com uma descrição das ideias pelas quais Kuhn atraiu para si a alcunha de irracionalista, ideias que envolvem a incomensurabilidade metodológica e a necessidade de elementos subjetivos na ciência. Em seguida, apresenta algumas das réplicas que Kuhn apresentou contra essas acusações, evidenciando sua convicção de que a ciência é, apesar de tudo que disse sobre ela, um empreendimento racional. Em paralelo a isso, mostra ainda sua oposição à ideia realista que vê o empreendimento científico como uma aproximação cada vez maior do "mundo real", oposição que se apoia na sua ideia de incomensurabilidade ontológica e no seu ataque à teoria correspondencial da verdade. Num terceiro momento, ele explica como o abandono do ideal realista de ciência vem a tornar-se o elemento essencial do modelo de racionalidade científica descrita por Kuhn em seus últimos escritos. O trabalho conclui com algumas considerações acerca das consequências desse modelo de racionalidade, consequências que fortalecerão a ideia de que existe uma relação entre racionalidade e antirrealismo no pensamento desse autor.

\section{O CAMINHO PARA A REVOLUÇÃO}

Thomas Kuhn ofereceu uma interpretação do desenvolvimento científico que rompe com as variadas formas que o precederam. Nessa interpretação ele diz que as

1 Conferir, por exemplo, o debate entre Paul Hoyningen-Huene e Eric Oberheim de um lado, e Howard Sankey do outro, cuja discordância gira em torno da atribuição ou não de um caráter realista à obra de Kuhn e à interpretação desta sob uma ótica kantiana. Esse debate, que vem acontecendo já há alguns anos, pode ser sintetizado nos textos mais recentes desses autores; de um lado HOYNINGEM-HUENE, P., \& OBERHEIM, E. Reference, ontological replacement and Neo-Kantianism: a reply to Sankey. Studies in History and Philosophy of Science, 40(2), pp.203-209, 2009, e do outro SANKEY, H. A curious disagreement: response to Hoyningen-Huene and Oberheim. Studies in History and Philosophy of Science 40, pp.210-212, 2009.

DIALEKTIKÉ, v. 1, novembro 2014, p. 3-16

Artigo submetido em setembro/2014 e aceito em outubro/2014 
ciências avançam através de grandes períodos de ciência normal separados por alguns momentos de ciência extraordinária. Na ciência normal cada especialidade científica realiza seus estudos sob a orientação de um paradigma, que fornece as diretrizes básicas para a pesquisa, como os problemas legítimos, modelos de solução, experimentos relevantes, etc., e a partir dos quais os cientistas se empenham na solução de quebracabeças, formas de articular a experiência com o paradigma, aumentando sua precisão, alcance e fecundidade.

Graças ao comprometimento dos praticantes de ciência com o paradigma, a comunidade científica passa a estudar a área por ele referida sem ter que recorrer todo tempo a um questionamento sobre suas bases, deixando assim o grupo desimpedido para aprofundar-se cada vez mais nas implicações dos princípios outrora aceitos. Daí Kuhn asseverar que a aquisição de um paradigma é um sinal de maturidade no desenvolvimento de qualquer campo científico, já que é ele que permite aquela pesquisa mais esotérica típica das ciências desenvolvidas.

Porém, não obstante o forte empenho com que o cientista tenta resolver os quebra-cabeças e articular o paradigma para que este possa dar conta de um número de fenômenos cada vez maior, há momentos em que as observações científicas não conseguem ser encaixadas nas predições paradigmáticas. A esse tipo de problema Kuhn chamou anomalia.

Quando a anomalia persiste mediante tentativas continuadas de articulação por parte de vários cientistas, começa a disseminar-se a desconfiança de que, não a prática, mas as próprias regras impostas pelo paradigma tornam a comunidade incapaz de resolver aquela anomalia. Kuhn diz que, "quando, por essas razões ou outras similares, uma anomalia parece ser algo mais do que um novo quebra-cabeça da ciência normal, é sinal de que se iniciou a transição para a crise e para a ciência extraordinária" (KUHN, 2005, p. 105).

Ainda segundo Kuhn, durante a ciência extraordinária existe um relaxamento das regras da ciência normal, originado pela incapacidade dos cientistas resolverem certas anomalias. Esse relaxamento permite o aparecimento de teorias alternativas que resolvam ou simplesmente considerem aquela anomalia irrelevante. Partindo da observação dessa diferença de tratamento dado ao problema gerador da crise, Kuhn sugere que as teorias

DIALEKTIKÉ, v. 1, novembro 2014, p. 3-16

Artigo submetido em setembro/2014 e aceito em outubro/2014 
alternativas diferem em alguns aspectos fundamentais do paradigma em crise, impossibilitando sua adesão e forçando os cientistas a escolherem entre os dois.

Quando dessa necessidade de escolha, continua ele, não existiria um conjunto de regras que servisse de tribunal ao qual os cientistas pudessem recorrer, já que tal tribunal exigiria assumir, de antemão, os postulados básicos de um paradigma em detrimento do outro, a fim de poder ter em mãos critérios básicos como "que tipo de problema um paradigma deve ser capaz de resolver?" ou "quais os métodos de pesquisa legítimos para a solução de problemas?". Por essa razão, cientistas de ambos os lados do debate precisariam, eventualmente, recorrer a elementos subjetivos e extra científicos para dar cabo dessa escolha, que, quando acontecia, constituía uma revolução científica.

Somado a isso, há ainda no texto de Kuhn várias ideias que despertaram polêmica, dentre as quais aquela segundo a qual "a competição entre paradigmas não é o tipo de batalha que possa ser resolvido por meio de provas" (KUHN, 2005, p.190), e que por isso "a transição entre paradigmas em competição não pode ser feita passo a passo, por imposição da lógica e de experiências neutras" (Ibid., p.192), e que algumas das razões pelas quais cientistas individuais abraçam um novo paradigma "encontram-se inteiramente fora da esfera aparente da ciência" (Ibid., p.195).

Assim, por defender a necessidade de elementos subjetivos nos momentos que tradicionalmente se acreditava serem os maiores exemplares da racionalidade científica, bem como a impossibilidade de apoiar esses momentos em discussões totalmente objetivas, Kuhn foi imediatamente taxado de "irracionalista" e "relativista"2.

Contudo, longe de concordar com essas críticas, Kuhn negou energicamente que essa fosse sua intenção, conforme ele deixa explícito em textos posteriores. Em um deles, ele diz

Eu não acredito, em momento algum, que a ciência seja um empreendimento intrinsecamente irracional. [...] Se a história ou qualquer outra disciplina empírica nos leva a crer que o desenvolvimento da ciência depende essencialmente do comportamento que antes pensávamos ser irracional, então não devemos concluir que a

$2 \mathrm{O}$ ataque que talvez melhor represente essas críticas é aquele feito por Imre Lakatos, para quem Kuhn "[...] exclui qualquer possibilidade de reconstrução racional do crescimento da ciência" (LAKATOS, 1979, p.220).

DIALEKTIKÉ, v. 1, novembro 2014, p. 3-16

Artigo submetido em setembro/2014 e aceito em outubro/2014 
ciência é irracional, mas que nossa noção de racionalidade precisa de ajustes aqui e ali (KUHN, 1987, p.91).

Por essa razão, ele procurou desenvolver uma argumentação que explicaria o real sentido de racionalidade científica que tinha em mente, e como ele próprio se encaixava nele, conforme mostramos na próxima seção.

\section{REVOLUCIONÁRIO SIM, IRRACIONALISTA NÃO}

O primeiro passo dessa argumentação foi expor o conceito de racionalidade científica usado pelos seus críticos. Em seguida, minar esse conceito, de forma que não mais se pudesse fazer uso dele de forma coerente. Por fim, apresentar um substituto que contemplasse toda a ciência, justificando a asserção pela qual ele afirmou ser este um empreendimento racional.

Quanto ao primeiro ponto, duas são as características principais do modelo de racionalidade que devem ser notadas aqui. Com efeito, são essas características as mais enfatizadas por Kuhn ao longo de seu ataque, e pode-se perceber uma estreita relação entre as duas nos seus últimos trabalhos.

A primeira característica diz respeito ao uso que o conceito tradicional de racionalidade científica faria de uma linguagem neutra e dos cânones da lógica para dar conta da justificação e escolha entre teorias. Com efeito, ao falar das diferenças fundamentais que o separavam de Karl Popper, Kuhn diz que

[e]le [Popper] e seus seguidores compartilham, com filósofos da ciência mais tradicionais, a suposição de que o problema da escolha de teorias pode ser resolvido por técnicas semanticamente neutras. [...] Para Sir Karl e sua escola, não menos do que para Carnap e Reichenbach, os cânones de racionalidade derivam, assim, exclusivamente dos cânones da sintaxe lógica e linguística (KUHN, 2006, p.160).

Dentro dessa concepção de racionalidade científica, o recurso à lógica como uma ferramenta de avaliação e comparação de teorias prestaria à ciência a mesma precisão e credibilidade de que já gozariam os procedimentos da lógica simbólica, credibilidade reconhecida pelo próprio Kuhn (2006, p.194). Na mesma ocasião, ele destaca ainda que

DIALEKTIKÉ, v. 1, novembro 2014, p. 3-16

Artigo submetido em setembro/2014 e aceito em outubro/2014 
tal processo exigiria uma linguagem comum que equiparasse os enunciados feitos por todas as teorias da mesma forma que os enunciados dentro de um argumento da lógica, condição de comparação e avaliação formal.

A segunda característica desse modelo de racionalidade, segundo Kuhn, é a adoção de uma meta científica específica. Segundo ele,

[n]a formulação principal da tradição pregressa em filosofia da ciência, as crenças deveriam ser avaliadas com respeito à sua verdade ou à probabilidade de serem verdadeiras, entendendo-se por verdade algo como correspondência ao real, ao mundo externo independente da mente (KUHN, 2006, p.143).

Assim, entendendo que na ciência uma decisão racional seria aquela que a aproximasse de sua meta, e sua meta sendo considerada a verdade ou uma probabilidade crescente de que suas teorias sejam verdadeiras, uma decisão racional deveria conduzir a enunciados cada vez mais verdadeiros sobre o mundo, o que vincula, no âmbito do modelo tradicional de racionalidade, o método científico a um caráter realista da ciência ${ }^{3}$.

Contudo, Kuhn lança dúvidas sobre a possibilidade tanto de se conceber uma linguagem neutra com fins de avaliação quanto de que a ciência possa ser avaliada quanto a sua aproximação da verdade sobre o mundo. Essas dúvidas podem ser ambas derivadas de uma única ideia, chamada por ele de incomensurabilidade semântica.

Primeiro, ele chama a atenção para o fato de que a observação dos dados científicos depende em grande parte da própria teoria a qual esses dados vão servir, ideia para a qual oferece vários exemplos, mostrando como a mesma observação pode ser interpretada de formas diferentes. Como consequência, ele defende que nos momentos de ciência extraordinária, alguns dos termos compartilhados por ambos os paradigmas mudam de significado, dificultando a comunicação entre partidários de paradigmas diferentes e colocando em dúvida o ideal de linguagem neutra e universal, bem como a

\footnotetext{
3 Embora haja espaço para dúvidas no que diz respeito à associação dessa ideia a todos os partidários do modelo tradicional de racionalidade científica, a tendência a relacionar esse modelo a tal ideia é corroborada por vários outros autores, dentre os quais estão Harold Brown, Larry Laudan, Newton-Smith e Bas van Fraassen.
}

DIALEKTIKÉ, v. 1, novembro 2014, p. 3-16

Artigo submetido em setembro/2014 e aceito em outubro/2014 
possibilidade daquela comparação objetiva e inequívoca inspirada nos procedimentos da lógica.

Segue-se daí que, como um dos elementos essenciais de uma visão realista da ciência é a igualdade de referência - com a qual podemos julgar se uma teoria representa uma maior aproximação da verdade que a anterior - a incomensurabilidade semântica implicaria também numa forma de antirrealismo, ou seja, na ideia de que a ciência não pode ser considerada um empreendimento que se aproxima de uma visão cada vez mais exata da realidade. Sobre isso Kuhn diz ainda que

[a]penas uma plataforma arquimediana fixa, rígida, poderia fornecer uma base para medir a distância entre a crença corrente e a verdadeira. $\mathrm{Na}$ ausência dessa plataforma, é difícil imaginar o que seria uma tal mensuração, o que poderia significar a expressão "cada vez mais perto da verdade" (KUHN, 2006, pp.144-145).

Talvez por essa razão esse autor acredite que "a comparação de teorias históricas não fornece nenhuma indicação de que suas ontologias estejam se aproximando de um limite" (KUHN, 2006, p.200), ideia para a qual ele oferece o exemplo da teoria da relatividade de Einstein, que - do ponto de vista ontológico - se pareceria muito mais com a física de Aristóteles do que com a de Newton.

A relação entre seu antirrealismo e a incomensurabilidade semântica é corroborada pela sua aversão ao uso da teoria correspondencial da verdade como um critério para avaliar o conteúdo de verdade de uma teoria, já que para ele "para aplicar essa concepção na comparação de duas teorias, é preciso supor, portanto, que seus proponentes concordem a respeito dos equivalentes técnicos de questões de fato, tais como saber se a neve é branca" (Ibid. p.200).

Por essa razão assumir a "verdade" como sendo a meta da ciência traz uma série de dificuldades, já que para isso a avaliação precisa ser indireta, ou seja, é preciso eleger um conjunto de critérios secundários que se passem por "indicadores de verdade", os quais as teorias devem satisfazer. É nesse sentido que têm sido entendidos os critérios usuais de avaliação de teorias, tais quais exatidão, amplitude, consistência, simplicidade, etc. Com efeito,

DIALEKTIKÉ, v. 1, novembro 2014, p. 3-16

Artigo submetido em setembro/2014 e aceito em outubro/2014 
[p]rosseguindo, portanto, com a formulação que prega ser a verdade a meta das avaliações, notem que ela requer que a avaliação seja indireta. Em ocasiões raras, ou nunca, pode-se comparar uma lei ou teoria recém-proposta diretamente com a realidade. Ao contrário, para propósitos de avaliação, é preciso inseri-la em um corpo relevante de crenças correntemente aceitas [...] e então aplicar ao todo um conjunto de critérios secundários. [...] Todos esses critérios são ambíguos e, raramente, satisfeitos todos de uma vez (KUHN, 2006, p.143).

Nota-se assim que tanto a negação do caráter lógico formal de racionalidade científica quanto da meta realista que esta adota são fruto da impossibilidade de uma linguagem neutra. Por essas razões, Kuhn propõe que se abandone esse modelo, ao qual ele oferece um substituto.

\section{RACIONALIDADE SEM REALIDADE}

O modelo de racionalidade oferecido por Kuhn parte exatamente de uma tentativa de contornar as dificuldades que ele apontou no modelo anterior. Com efeito, para ele, na impossibilidade de comparar as crenças diretamente com a natureza tudo que resta aos cientistas é uma comparação de paradigmas com outros paradigmas. O próprio Kuhn já havia dito que, uma vez que um determinado campo científico alcançasse seu primeiro paradigma, já não seria possível a pesquisa na sua ausência ou na de um substituto. Depois que um primeiro paradigma fosse assumido, todo processo de escolha deveria ser comparativo, mas não com a natureza, e sim com outro paradigma. Segundo ele

[...] uma teoria científica, após ter atingido o status de paradigma, somente é considerada inválida quando existe uma alternativa disponível para substituí-la. Nenhum processo descoberto até agora pelo estudo histórico do desenvolvimento científico assemelha-se ao estereótipo metodológico da falsificação por meio da comparação direta com a natureza. [...] decidir rejeitar um paradigma é sempre decidir simultaneamente aceitar outro e o juízo que conduz a essa decisão envolve a comparação de ambos os paradigmas com a natureza, bem como sua comparação mútua (KUHN, 2005, p.108).

DIALEKTIKÉ, v. 1, novembro 2014, p. 3-16

Artigo submetido em setembro/2014 e aceito em outubro/2014 
Essa convicção é reforçada em seus últimos escritos, de acordo com os quais o que está em questão para o filósofo da ciência que estuda a racionalidade inerente ao seu desenvolvimento não é a crença em si, mas a mudança de crença. Em outras palavras, ele diz que a avaliação deve incidir sobre os processos pelos quais os cientistas resolveram abandonar certas convicções científicas em prol de outras. Dessa forma, a racionalidade da ciência é uma avaliação que incide sobre momentos de troca de paradigmas, isto é, na comparação de paradigma com paradigma, e não de paradigmas diretamente com a natureza ${ }^{4}$.

Em adição a isso, Kuhn também explica que a racionalidade deve vigorar como um procedimento pelo qual cientistas fazem escolhas no sentido de maximizar a aproximação da ciência a um objetivo específico, ideia que o coloca ao lado dos proponentes do modelo tradicional. Nesse sentido, se a meta da ciência for considerada, por exemplo, uma explicação cada vez mais abrangente do mundo, será racional escolher uma teoria mais ampla em detrimento de uma mais restrita, e irracional fazer o contrário.

Contudo, ao contrário dos proponentes do modelo tradicional, Kuhn oferece um substituto à ideia de que a meta da ciência seria a verdade sobre o mundo, e que, enquanto tal, supere as dificuldades que ele já havia apontado para aqueles que adotassem esse objetivo. Com efeito, ao referir-se ao cientista ele diz que "[...] a solução de um difícil quebra-cabeça conceitual ou instrumental representa uma meta principal” (KUHN, 1970, p.71).

Assim, eleita a resolução de quebra-cabeças como a meta da ciência, uma decisão racional será escolher das teorias disponíveis aquela que dispõe de um melhor instrumental para esse propósito. E essa escolha pode ser levada a cabo usando os mesmos critérios elencados anteriormente, mas agora de forma direta, já que a própria definição de quebra-cabeças inclui tais critérios.

Exatidão, precisão, alcance, simplicidade, fertilidade, consistência etc. simplesmente são os critérios que os solucionadores de quebra-cabeças devem sopesar ao decidir se determinado quebra-cabeça sobre a

4 Essas ideias encontram-se principalmente nos textos 'O caminho desde A estrutura', 'O problema com a filosofia histórica da ciência' e 'Pós-escritos' - todos presentes em KUHN, 2006 - e respondem pelo título de perspectiva histórica ou perspectiva evolucionária.

DIALEKTIKÉ, v. 1, novembro 2014, p. 3-16

Artigo submetido em setembro/2014 e aceito em outubro/2014 
correspondência entre fenômenos e crenças foi ou não resolvido (KUHN, 2006, p.307).

Partindo dessa mesma interpretação, Jouni Kukkanen defende uma aproximação da filosofia de Kuhn com uma epistemologia coerentista, aquela que identifica a verdade com uma maior coerência dos enunciados envolvidos. Assim, a busca por uma melhor capacidade de resolução de quebra-cabeças poderia ser associada à busca de uma verdade como coerência, diferente de uma verdade por correspondência (KUUKANEN, 2007, pp.555-556). Essa ideia parece corresponder à aversão de Kuhn à teoria correspondencial da verdade e também com sua asserção de que "[...]"verdade", como "prova", pode ser um termo de aplicações apenas intrateóricas" (KUHN, 2006, p.200).

Percebe-se assim que, para Kuhn, o abandono do ideal realista torna a ciência um empreendimento racional, já que a mudança de crença não pode ser julgada racionalmente se ela almejar a verdade sobre o mundo, mas apenas se buscar uma melhor capacidade para resolver quebra-cabeças.

\section{ANTIRREALISMO ANTES DE TUDO}

Foi dito mais acima que tanto a recusa do ideal de aproximação da verdade quanto o caráter lógico formal de racionalidade estavam vetadas pela incomensurabilidade semântica. Sendo assim, tanto a adoção de uma maior capacidade para resolução de quebra-cabeças como meta da ciência quanto um modelo de racionalidade não formal seriam elementos relacionados de forma necessária, o que justificaria por que razão Kuhn colocou uma tese antirrealista na base de seu modelo de racionalidade.

Contudo, se for demonstrado que a adoção dessa tese não se segue necessariamente da impossibilidade de uma linguagem neutra, a relação entre a meta escolhida por Kuhn e seu modelo de racionalidade também perdem seu caráter necessário, sugerindo que o antirrealismo de Kuhn é um elemento injustificado e anterior de sua filosofia.

Com efeito, Howard Sankey defende, ao longo de alguns de seus trabalhos, uma interpretação da filosofia de Kuhn segundo a qual a variação de sentido da linguagem

DIALEKTIKÉ, v. 1, novembro 2014, p. 3-16

Artigo submetido em setembro/2014 e aceito em outubro/2014 
utilizada por paradigmas sucessivos pode ser encaixada em uma perspectiva realista da ciência. Para isso Sankey dá uma breve caracterização do realismo científico e das teses que ele envolve, a fim de demonstrar como a incomensurabilidade não representa um real desafio ao realismo. Entre elas está a ideia de que a meta da ciência é descobrir a verdade sobre o mundo, e que o progresso científico consiste no avanço em direção a essa meta. Em segundo lugar está o uso que o realista faz da teoria correspondencial da verdade como um critério para avaliar a verdade dos enunciados feitos pelas teorias. Ainda, o realismo científico implica num realismo metafísico, isto é, na ideia de que o mundo estudado pela ciência é um mundo real, independente da mente.

Tendo isso em mãos, Sankey continua seu argumento, agora negando que a incomensurabilidade vá de encontro a essas ideias. Em primeiro lugar, segundo ele, a negação que a incomensurabilidade faz da ideia de progresso científico baseado no avanço em direção à verdade pode ser contornada. Com efeito, a interpretação usual da incomensurabilidade é que, ao mudar o sentido dos termos usados em paradigmas diferentes, ela mudaria também suas referências, impossibilitando uma comparação interparadigmática de objetos. Mas essa relação sentido-referência - a qual se reporta àquela descrita por Frege - não é a única possível. Os teóricos causais da referência têm argumentado que a referência é estabelecida anterior e independentemente do sentido a ela associado, e que por isso não é sensível à variação de sentido imposta pela mudança de paradigma. Assim, garantida a correferencialidade entre paradigmas, estaria disponível o elemento essencial pelo qual poderíamos avaliar se paradigmas sucessivos dão descrições mais verdadeiras sobre certos objetos.

Em segundo lugar, o ataque de Kuhn à teoria correspondencial da verdade não é efetivo. Com efeito, ele falha ao entendê-la como uma teoria epistemológica, uma forma de sabermos se uma teoria científica é ou não verdadeira, quando na verdade o que a teoria da correspondência faz é nos dar um critério ontológico de verdade, independente dos meios de conhecer essa verdade, mal entendido também notado por Bird (2000, pp.225-227) e Hoyningen-Huene (1993, pp.263-264).

Por fim, a existência de um mundo real, independente da mente, não é posta em dúvida por Kuhn, para quem "não importa o que o cientista possa então ver, após a revolução o cientista ainda está olhando para o mesmo mundo" (KUHN, 2005, p.168).

DIALEKTIKÉ, v. 1, novembro 2014, p. 3-16

Artigo submetido em setembro/2014 e aceito em outubro/2014 
Com isso, pode-se chegar a uma conclusão análoga a de Bird, que ao concordar com Sankey em sua interpretação realista da incomensurabilidade diz que

[...] embora seja verdade que Kuhn seja um antirrealista epistemológico enquanto adere a tese da incomensurabilidade, não é o caso, contrariamente a visão comum, que seu antirrealismo se siga da tese da incomensurabilidade. A tese da incomensurabilidade é muito fraca para suportar tal inferência (BIRD, 2003, p.692).

Logo, o antirrealismo de Kuhn é um elemento injustificado de sua filosofia da ciência, mas do qual, no entanto, ele faz uso em sua teoria da racionalidade científica. Em outras palavras, embora Kuhn seja um antirrealista, essa posição não pode ser justificada com base nas suas observações sobre a ciência. Logo, seu antirrealismo é um elemento contingente, porém central em sua teoria da ciência.

\section{CONCLUSÃO}

Com a exposição feita até aqui o trabalho não pretende defender que a teoria da racionalidade de Kuhn é algo infundado. Com efeito, ele deixa em aberto a questão acerca de que outras bases poderiam suportar uma teoria da racionalidade como a exposta acima. Seu ponto é apenas que o antirrealismo de Kuhn é algo anterior a suas outras considerações sobre a natureza da ciência, em especial sua teoria da racionalidade, o que mostra que a relação entre suas ideias acerca da relação entre racionalidade e realidade são bem mais profundas do que se poderia inferir de uma leitura menos cuidadosa. Nesse sentido pode concluir apenas que qualquer interpretação que ignore a relação entre as ideias de Kuhn sobre esses dois temas corre o risco de fazer um retrato nada mais do que parcial desse filósofo.

\section{REFERÊNCIAS}

BIRD, A. Kuhn, nominalism, and empiricism. Philosophy of Science 70: pp.690-719, 2003.

DIALEKTIKÉ, v. 1, novembro 2014, p. 3-16

Artigo submetido em setembro/2014 e aceito em outubro/2014 
BIRD, A. Thomas Kuhn. Acumen, 2000.

BROWN, H. Rationality. London and New York: Routledge, 1990.

HACKING, I. Representar e intervir; tópicos introdutórios de filosofia da ciência natural. Tradução de Pedro Rocha de Oliveira. Rio de Janeiro, EdUERJ, 2012.

HOYNINGEN-HUENE, P. Reconstructing scientific revolutions. Chicago: University of Chicago Press, 1993.

HOYNINGEN-HUENE, P., \& OBERHEIM, E. Reference, ontological replacement and Neo-Kantianism: a reply to Sankey. Studies in History and Philosophy of Science, 40(2), pp.203-209, 2009.

KUHN, T. S. O caminho desde A estrutura. Tradução de Cezar Mortari. São Paulo: Unesp, 2006.

A estrutura das revoluções científicas. Tradução de Beatriz Vianna Boeira e Nelson Boeira. $9^{\circ}$ ed. São Paulo: Perspectiva, 2005.

Notas sobre Lakatos. In Historia de la ciencia y sus reconstrucciones racionales. Tradução de Diego Ribes Nicolás. Madrid, Espanha: Editorial Tecnos S.A., pp.79-95, 1987.

Logic of Discovery or Psychology of Research? In LAKATOS, I.; MUSGRAVE, A. Criticism and the growth of knowledge: Proceeding of the International colloquium in the philosophy of Science, London, 1965, volume 4. Cambridge University Press, pp.123, 1970.

KUUKKANEN, J. Kuhn, the correspondence theory of truth and coherentist epistemology. In: Studies in history and philosophy of science 38, pp.555-566, 2007.

LAKATOS, I. O falseamento e a metodologia dos programas de pesquisa. In: LAKATOS, I.; MUSGRAVE, A. A crítica e o desenvolvimento do conhecimento: quarto volume das atas do Colóquio Internacional sobre Filosofia da Ciência, realizado em Londres em 1965. Tradução de Octavio Mendes Cajado. São Paulo: Cultrix, pp.109-243, 1979.

LAUDAN, L. Progress and Its Problem. Berkeley, Los Angeles and London: University of California Press, 1977.

NEWTON-SMITH, W.H. The rationality of Science. Taylor \& Francis e-Library, 2003.

POPPER, K. R. Conjecturas e refutações: o progresso do conhecimento científico. Tradução de Sérgio Bath. 5 ed. Brasília: Editora Universidade de Brasília. 2008.

DIALEKTIKÉ, v. 1, novembro 2014, p. 3-16

Artigo submetido em setembro/2014 e aceito em outubro/2014 
SANKEY, H. Taxonomic incommensurability. Disponível em http://philosophy.unimelb.edu.au/about/staff/Sankey/howard/howardpaper6.PDF. Acesso em julho de 2011.

A curious disagreement: response to Hoyningen-Huene and Oberheim. Studies in History and Philosophy of Science 40, pp.210-212, 2009.

Scientific realism and the rationality of science. Ashgate, Aldershot, 2008.

Incommensurability: The current state of play. Theoria 12, pp.425-445, 1997.

TIANJI, J. Scientific Rationality, Formal or Informal? British Journal for the Philosophy of Science, vol. 36, pp. 409-23, 1985.

DIALEKTIKÉ, v. 1, novembro 2014, p. 3-16

Artigo submetido em setembro/2014 e aceito em outubro/2014 